\title{
PROPOSAL FOR INCREASE OF BURGLAR RESISTANCE OF COMMERCIALLY MANUFACTURED MOTOR VEHICLE DOORS
}

In many cases the level of personal protection especially during transportation by personal motor vehicles is dependent on burglar resistance of used car body materials. Currently commercially manufactured personal motor vehicles are modified by insertion offiller materials of high density (steel plates inserted into doors, steel reinforcements of vehicle floors). This approach causes not only increase in financial costs for procurement of such modified (armoured) vehicle, but also changes its driving characteristics. Particularly its financial cost affects its accessibility to wide public. Several cases of use of small firearms against the occupants of commercially manufactured personal motor vehicles have been investigated in recent years. The results of such attacks were casualties or grievous bodily harm. Considered materials were experimentally tested for the purpose of increasing burglar resistance mainly of commercially manufactured motor vehicle doors and increase of their burglar resistance against shots from small firearms. The result of experiments that were carried out was the recommendation for reinforcement of car body doors of personal motor vehicles using molten polycarbonate materials. The thickness of $24 \mathrm{~mm}$ resulted in such increase of door burglar resistance that used small firearm ammunition could not penetrate this barrier.

Keywords: Person and property protection, security, burglar resistance, bullet, ammunition, reinforced, personal motor vehicle, self-loading firearm.

\section{Introduction}

State of protection of persons and property level follows development of external and internal security environment in which they operate. An important indicator of security or risk level is criminality, especially the violent crime. Democratization of firearm ownership created relatively new phenomenon of security risk which until now correlated mainly with contracted attacks focused on lives and health of risk groups of persons (e.g. important political officials, members of the Government or Justice, ambassadors, members of criminal organizations, etc.) In recent period, relatives of risk group members, transporters of cash or valuables and ordinary citizens have also become targets of contracted violent attacks. Potential victims of assaults with weapon become most vulnerable mainly during transportation by motor vehicles. This status results from the nature of utilization of motor vehicle transportation. Potential victims are limited then not only by road infrastructure, but also by internal space of the vehicle which impedes their defense. Relying on passive protection elements of vehicles is possible only in vehicles in which special modifications were carried out, enhancing their burglar resistance against attacks utilizing firearms. Vehicles reinforced, for example by armor, provide high level of protection to their crew. Commercially produced vehicles are reinforced [1]. These are able to maintain the original technical and driving characteristics after modification. High cost of said types of personal motor vehicles, as well as the modifications, significantly lowers their availability to wider public (average price of reinforced personal motor vehicle moves around $200000 €$ ). For this reason, the target customers of modified (armoured) vehicles are mainly politicians, ambassadors, entrepreneurs or bosses of criminal organizations. Other concerned groups of persons are insufficiently protected against attacks with firearms from the viewpoint of burglar resistance of commercially used vehicles.

\section{Problem description}

Currently most of providers of personal motor vehicles reinforcement prefer steel sheets which provide high level

\footnotetext{
* ${ }^{1}$ Kamil Boc, ${ }^{2}$ Dagmar Vidrikova, ${ }^{3}$ Zoran Cekerevac, ${ }^{4}$ Jan Misik

${ }^{1}$ Department of Security Management, Faculty of Security Engineering, University of Zilina, Slovakia

${ }^{2}$ Department of Technical Sciences and Informatics, Faculty of Security Engineering, University of Zilina, Slovakia

${ }^{3}$ Faculty of Business and Industrial Management, Union University Belgrade, Serbia

${ }^{4}$ Department of Security Management, Faculty of Security Engineering, University of Zilina, Slovakia

E-mail: Kamil.Boc@fbi.uniza.sk
} 


\begin{tabular}{|c|c|c|c|c|c|c|c|c|}
\hline \multicolumn{9}{|c|}{ Euronorm Standard For Security Glazing } \\
\hline Class & Weapon & Calibre & Type & Weight (g) & Range (m) & $\operatorname{Velocity}(m / s)$ & Impact Energy & Shots \\
\hline BR1 & Handgun/Rifle & $.22 \mathrm{LR}$ & $\mathrm{LB} / \mathrm{RN}$ & $\begin{array}{c}2.6 \\
\pm 0.1\end{array}$ & $\begin{array}{l}10.00 \\
\pm 0.5\end{array}$ & $\begin{array}{r}360 \\
\pm 10\end{array}$ & $170 \mathrm{~J}$ & 3 \\
\hline BR2 & Handgun & $\begin{array}{l}\text { 9x19mm } \\
\text { Parabellum }\end{array}$ & $\mathrm{FJ} / \mathrm{RN} / \mathrm{SC}$ & $\begin{array}{c}8,0 \\
\pm 0.1\end{array}$ & $\begin{array}{l}5.00 \\
\pm 0.5\end{array}$ & $\begin{array}{l}400 \\
\pm 10\end{array}$ & $640 \mathrm{~J}$ & 3 \\
\hline BR3 & Handgun & .357 Magnum & $\mathrm{FJ} / \mathrm{CB} / \mathrm{SC}$ & $\begin{array}{l}10.2 \\
\pm 0.1\end{array}$ & $\begin{array}{l}5.00 \\
\pm 0.5\end{array}$ & $\begin{array}{r}430 \\
\pm 10 \\
\end{array}$ & $940 \mathrm{~J}$ & 3 \\
\hline BR4 & Handgun & .44 Magnum & $\mathrm{FJ} / \mathrm{FN} / \mathrm{SC}$ & $\begin{array}{l}15.6 \\
\pm 0.1\end{array}$ & $\begin{array}{l}5.00 \\
\pm 0.5\end{array}$ & $\begin{array}{l}440 \\
\pm 10\end{array}$ & $1510 \mathrm{~J}$ & 3 \\
\hline BR5 & Rifle & $\begin{array}{l}5.56 \times 45 \mathrm{~mm} \\
\text { NATO }\end{array}$ & $\mathrm{FJ} / \mathrm{PB} / \mathrm{SCP}$ & $\begin{array}{c}4,0 \\
\pm 0.1\end{array}$ & $\begin{array}{l}10.00 \\
\pm 0.5\end{array}$ & $\begin{array}{l}950 \\
\pm 10\end{array}$ & $1800 \mathrm{~J}$ & 3 \\
\hline BR6 & Rifle & $\begin{array}{c}7.62 \times 51 \mathrm{~mm} \\
\text { NATO }\end{array}$ & $\mathrm{FJ} / \mathrm{PB} / \mathrm{SC}$ & $\begin{array}{c}9.5 \\
\pm 0.1\end{array}$ & $\begin{array}{l}10.00 \\
\pm 0.5\end{array}$ & $\begin{array}{r}830 \\
\pm 10\end{array}$ & $3270 \mathrm{~J}$ & 3 \\
\hline BR7 & Rifle & $\begin{array}{l}7.62 \times 51 \mathrm{~mm} \\
\text { NATO }\end{array}$ & $\mathrm{FJ} / \mathrm{PB} / \mathrm{HC}$ & $\begin{array}{c}9.8 \\
\pm 0.1\end{array}$ & $\begin{array}{l}10.00 \\
\pm 0.5\end{array}$ & $\begin{array}{r}820 \\
\pm 10\end{array}$ & $3290 \mathrm{~J}$ & 3 \\
\hline $\begin{array}{l}L B- \\
R N- \\
S C-\end{array}$ & $\begin{array}{l}\text { d Bullet } \\
\text { Ind Nose } \\
\text { Core (lead) }\end{array}$ & & $\begin{array}{l}\text { FJ - Full } 1 \\
C B \text { - Cone } \\
\text { SCP - Soft }\end{array}$ & $\begin{array}{l}\text { lacket } \\
\text { (lead) \& Stee }\end{array}$ & etrator & $\begin{array}{l}F N \\
P B \\
H C\end{array}$ & $\begin{array}{l}\text { Fat Nose } \\
\text { ointed Bullet } \\
\text { Iard core }\end{array}$ & \\
\hline
\end{tabular}

of burglar resistance against effects of firearms due to their characteristics. Disadvantages of their use lie in increased mass of vehicle and related modification of its construction (necessary above limit modifications of motor unit, construction of vehicle, suspension setup, etc.). International ballistic standards (e. g., EN 1063 - Glass in building. Security glazing. Testing and classification of resistance against bullet attack, EN 1522 - Windows, doors, shutters and blinds. Bullet resistance. Requirements and classification, EN 1523 - Windows, doors, shutters and blinds. Bullet resistance. Test method, German ballistic standard DIN 52 290) are applied to increase burglar resistance of commercially produced vehicles. These norms set seven classes of vehicle resistance against attacks mounted by different types of weapons (Table 1) [2 - 5].

Burglar resistance of commercially produced personal motor vehicles available in Slovakia became object of our experimental examination within VEGA project No. 1/098/11 Model of Integrated Security System Optimization Framework for Protection of Specific Objects Realised by Means of Expert System. The goal was to ascertain level of burglar resistance especially of vehicle doors which belong to critical parts of chassis, and propose means for its improvement [7]. Criteria of the proposal were affordability of the proposed modifications, minimal interference with vehicle construction and maintaining of its mass to exclude negative change of its technical and driving characteristics (e. g. mass changes up to $65 \%$ of original vehicle mass after modification). A self-loading handgun was selected for the experiment according to ballistic standards. Its s selection was based on availability and legality of its ownership. Dynamic development of number of holders and registered weapons in SR in recent years was taken into account (Fig. 1) [8 and 9].

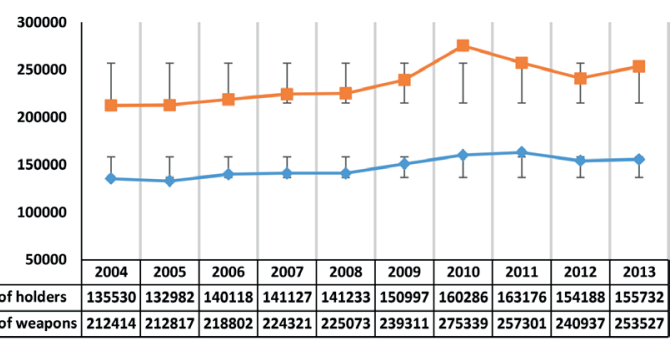

Fig. 1 Development of holders and registered weapons count in the Slovak Republic in the years 2004-2013 including standard deviation, trend line and reliability equation $R^{2}[10]$.

According to statements of experts from Police Force and firearm dealers, the prevailing interest of holders of firearm licences lies mainly in self-loading handguns.

\section{Methodology of experiment}

Input data necessary for performance of the experiment were acquired within the pilot project. During its performance, burglar resistance of chassis of commercially produced motor vehicles was tested, specifically the door of personal motor vehicle (hereinafter "test sample") available at Slovak market. All accessories (glass, locking mechanism, electronics, etc.) were removed from the test sample before the main testing. Methods 
of the examination within the pilot project, as well as the main experiment, were compliant with norm EN 1063 [2].

\subsection{Pilot project}

The pilot project was carried out in two stages. During the first stage, the burglar resistance of non-reinforced door was tested. During the second stage the door was reinforced by rock wool filling.

The test device consisted of a solid wooden frame on which the test sample (automobile door) was mounted. The mounting of test sample in frame:

- matches the standard car door mounting,

- distance from wall stopping the shots was $260 \mathrm{~mm}$,

- distance from muzzle was $10000 \mathrm{~mm}$,

- height from ground level was $690 \mathrm{~mm}$,

- perpendicular to the direction of shots,

- total target area was at minimum $440 \mathrm{~mm}$ x $440 \mathrm{~mm}$,

- selection of necessary mounting pressure to ensure the door edges did not move during the test, but also not to cause tension which could influence the test results [2].

Fragments of the shots or sheet metal loose from the test sample were stopped by the wall placed behind the test sample.
The wall consisted of masonry blocks made of autoclaved aerated concrete (compliant with norm EN 771-4, category 1) [11] arranged in two rows, each four pieces high. The masonry blocks were set in distance of $260 \mathrm{~mm}$ from the test sample. Height of the wall for stopping of shots and their fragments was $996 \mathrm{~mm}$, width from the front side $599 \mathrm{~mm}$, width from the side $750 \mathrm{~mm}$. The scattering of shots or sheet metal fragments was mapped by the control paper. Control paper consisted of white paper with density of $110 \mathrm{~g} / \mathrm{m} 2$. It was attached to the wall for stopping shots in vertical position, $320 \mathrm{~mm}$ behind the test sample. Its free surface was at least $440 \mathrm{~mm} \times 440 \mathrm{~mm}$, matching the target surface [3].

\section{Ballistic testing device}

Ballistic testing device was a self-loading firearm from Glock which belongs to the most widespread and most used types. Based on the selected type of weapon we focused on resistance class BR2. Technical parameters of used firearm and ammunition are listed in Table 2.

Rock wool Nobasil, type MPN of dimensions 1000 x 500 x $50.615 \mathrm{~mm}$ was used to reinforce the test sample. Process according to standard EN AW 6106 was followed for measuring metal sheet characteristics (Table 3) [12].

Technical parameters of used types of ammunition and weapon in pilot project [6]

Table 2

\begin{tabular}{|c|c|c|}
\hline \multicolumn{2}{|l|}{ Brand } & Glock \\
\hline \multicolumn{2}{|l|}{ Model } & 19 \\
\hline \multicolumn{2}{|c|}{ Produced in } & 2006 \\
\hline \multicolumn{2}{|l|}{ Calibre } & $9 \times 19 \mathrm{~mm}$ \\
\hline \multicolumn{2}{|c|}{ Length (frame) } & $174 \mathrm{~mm}$ \\
\hline \multicolumn{2}{|c|}{ Height with magazine } & $127 \mathrm{~mm}$ \\
\hline \multicolumn{2}{|c|}{ Width } & $30 \mathrm{~mm}$ \\
\hline \multirow{4}{*}{ Barrel } & Sight & $153 \mathrm{~mm}$ \\
\hline & Length & $102 \mathrm{~mm}$ \\
\hline & Profile & Clockwise \\
\hline & Grooves & 6 \\
\hline \multicolumn{2}{|c|}{ Magazine capacity } & 15 \\
\hline \multirow{3}{*}{ Weight } & no magazine & $595 \mathrm{~g}$ \\
\hline & empty magazine & $70 \mathrm{~g}$ \\
\hline & full magazine & 225 \\
\hline \multicolumn{2}{|c|}{ Muzzle velocity $V_{0}$} & $350 \mathrm{~ms}^{-1}$ \\
\hline \multicolumn{2}{|c|}{ Shot energy $E_{0}$} & $490 \mathrm{~J}$ \\
\hline \multicolumn{2}{|c|}{ Trigger travel distance } & $12.5 \mathrm{~mm}$ \\
\hline \multicolumn{2}{|c|}{ Trigger pull weight } & $2.0 \mathrm{~kg}$ \\
\hline
\end{tabular}

\begin{tabular}{|c|c|c|c|c|c|}
\hline $\begin{array}{l}\text { Pilot } \\
\text { project }\end{array}$ & & $\begin{array}{l}\text { 9mm LUGER } \\
\text { Magtech }\end{array}$ & $\begin{array}{l}\text { 9mm LUGER Lapua } \\
\text { Cepp Super FMJ }\end{array}$ & $\begin{array}{l}\text { RL } 124 \\
\text { GRS FMJ }\end{array}$ & $\begin{array}{l}\text { RL } 124 \text { GRS } \\
\text { FMJ lead }\end{array}$ \\
\hline \multicolumn{2}{|c|}{ Producer } & Magtech & Lapua & Not listed & \\
\hline \multicolumn{2}{|l|}{ Type } & FMC & FMJ & & \\
\hline \multirow{2}{*}{ Material } & case & \multicolumn{4}{|c|}{ CuZn (brass) } \\
\hline & bullet & \multicolumn{4}{|c|}{ Lead core covered by metal jacket } \\
\hline \multicolumn{2}{|c|}{ Shot weight } & $\begin{array}{c}7.45 \mathrm{~g} \\
(115 \mathrm{grs})\end{array}$ & $\begin{array}{c}7.80 \mathrm{~g} \\
(120 \mathrm{grs})\end{array}$ & $\begin{array}{c}7.95 \mathrm{~g} \\
(124 \mathrm{grs})\end{array}$ & $\begin{array}{c}9.83 \mathrm{~g} \\
(150 \mathrm{grs})\end{array}$ \\
\hline \multicolumn{2}{|l|}{ Primer } & \multicolumn{2}{|r|}{ Boxer } & \multicolumn{2}{|c|}{ Not listed } \\
\hline \multicolumn{2}{|c|}{ Shot speed $\mathrm{v}_{0}$} & $346 \mathrm{~ms}^{-1}$ & $360 \mathrm{~ms}^{-1}$ & \multicolumn{2}{|c|}{$350 \mathrm{~ms}^{-1}$} \\
\hline \multicolumn{2}{|c|}{ Shot energy $E_{0}$} & $446 \mathrm{~J}$ & $506 \mathrm{~J}$ & $487 \mathrm{~J}$ & $602 \mathrm{~J}$ \\
\hline
\end{tabular}


Technical parameters of test sample metal sheet [6]

Table 3

\begin{tabular}{|c|c|c|c|c|c|c|c|c|}
\hline \multirow{2}{*}{$\begin{array}{l}\text { Thickness } \\
(\mathrm{mm})\end{array}$} & \multirow{2}{*}{$\begin{array}{l}\text { Width } \\
(\mathrm{mm})\end{array}$} & \multirow{2}{*}{$\begin{array}{c}\text { Length } \\
(\mathrm{mm})\end{array}$} & \multirow{2}{*}{$\begin{array}{l}\text { Weight } \\
\text { (g) }\end{array}$} & \multirow{2}{*}{$\begin{array}{l}\text { Force } \\
(k N)\end{array}$} & \multirow{2}{*}{$\begin{array}{l}\text { Rigidity } \\
\left(\mathrm{Nmm}^{-2}\right)\end{array}$} & \multicolumn{2}{|c|}{ Length } & \multirow{2}{*}{ Ductility (\%) } \\
\hline & & & & & & before & after & \\
\hline .9 & 49 & 500 & 139.2 & 12.31 & 279.1 & 400 & 476 & 19 \\
\hline
\end{tabular}

Calculation of impact kinetic energy $\mathrm{E}_{\mathrm{d}}$ was based on following formula

$E_{d}=\frac{1}{2} m_{q} \cdot v_{d}^{2} \quad[\mathrm{~J}]$

where vd - impact speed of shot $\left[\mathrm{ms}^{-1}\right]$ and $\mathrm{mq}$ - weight of shot $[\mathrm{kg}]$

Mathematic model according to DeMarre was used for calculation of limit impact speed which applies to piercing of armour by armour-piercing shot [13]. It was assumed that all impact kinetic energy of the shot Ed should be consumed when piercing the sheet metal. Based on this assumption, the impact speed may be considered equal to limit speed ( $\mathrm{vd}=$ vlim). For calculation of limit impact speed $\mathrm{v}_{\mathrm{lim}}$ following empiric relationship was derived:

$v_{\lim }=K \cdot \frac{d^{\alpha}}{m_{q}^{\beta}} \cdot s^{\gamma}\left[m s^{-1}\right]$

where $\mathrm{v}_{\text {lim }}$ - limit impact speed of the shot $\left[\mathrm{ms}^{-1}\right], d$ - shot calibre [dm], $m_{q}$ - shot weight $[\mathrm{kg}], K$ - penetration force constant and $s$ - thickness of penetrated material [dm].

Based on shooting tests, several authors determined values of coefficients $\alpha, \beta, \gamma$ demonstrated in Table 4 [14 and 15].

Values of coefficients $\alpha, \beta, \gamma$ determined

by experiments [ 6 and 16$]$

Table 4

\begin{tabular}{|l|c|c|c|}
\hline Coefficient & $\boldsymbol{\alpha}$ & $\boldsymbol{\beta}$ & $\boldsymbol{\gamma}$ \\
\hline Euler & 1.0 & $1 / 2$ & $1 / 2$ \\
\hline Noble & $1 / 2$ & $1 / 2$ & 1.0 \\
\hline Krupp laboratory & $5 / 6$ & $1 / 2$ & $1 / 3$ \\
\hline DeMarre & .75 & $1 / 2$ & .7 \\
\hline
\end{tabular}

Following formula in DeMarre's form was used for determination of shot penetration:

$v_{\lim }=K \cdot \frac{d^{0,75}}{m_{q}^{0,5}} \cdot s^{0,7 \gamma}\left[m s^{-1}\right]$

Characteristics of the penetration of the test sample material are determined by penetration force constant $K$. Its value was set by the authors for purpose of this project empirically at $\mathrm{K}=2400$. Calculation of values of impact kinetic energy and limit impact speed of used shots for overcoming the resistance of the sheet metal (penetration) are listed in Table 5.

Calculated values of impact kinetic energy and limit impact speed of used shots for penetrating the test sample during pilot project [6]

Table 5

\begin{tabular}{|l|c|c|}
\hline Brand & $\boldsymbol{E d}(\boldsymbol{J})$ & $\boldsymbol{V}_{\text {lim }}\left(\boldsymbol{m s}^{\mathbf{I}}\right)$ \\
\hline MAGTECH & 445.94 & 168.96 \\
\hline LAPUA CEPP SUPER & 505.44 & 165.13 \\
\hline Reloaded RL 124 GRS & 486.93 & 163.56 \\
\hline
\end{tabular}

\subsection{Main experiment}

Main experiment followed upon the results of the pilot project. Its goal was to verify the burglar resistance of test sample which was reinforced by cast polycarbonate. Testing device was similar to the one used in the pilot project. Ballistic testing device was replaced by handheld self-reloading Glock, model 19, made in 2012. Relevant technical parameters are similar to the technical parameters of weapon listed in Table 2. For the purpose of reaching higher penetration of the shot, 4 types of ammunition were used. Their technical parameters are listed in Table 6 . The shooting distance was decreased to $5 \mathrm{~m} \mathrm{[17].}$

Technical parameters of used ammunition [6]

Table 6

\begin{tabular}{|c|c|c|c|c|c|}
\hline \multicolumn{2}{|c|}{ Main experiment } & 9mm LUGER ZVS & 9mm LUGER Subsonic & 9mm LUGER & Blazer 9mm LUGER \\
\hline \multicolumn{2}{|c|}{ Producer } & ZVS Holding & \multicolumn{2}{|c|}{ Sellier \& Bellot ČR } & FCC USA \\
\hline \multicolumn{2}{|c|}{ Type } & FMJ RN & FMJ & JHP & $\mathrm{AL}$ \\
\hline \multirow{2}{*}{ Material } & case & $\mathrm{CuZn}$ & CuZn 30 & CuZn 10 & $\mathrm{AL}$ \\
\hline & bullet & \multicolumn{2}{|c|}{ Lead core, full metal } & Lead core, half metal & Lead core, full metal \\
\hline \multicolumn{2}{|c|}{ Bullet weight } & $7.45 \mathrm{~g}$ (115grs) & $9.70 \mathrm{~g}$ (150grs) & $7.50 \mathrm{~g}(115 \mathrm{grs})$ & $7.45 \mathrm{~g}$ (115grs) \\
\hline \multicolumn{2}{|c|}{ Primer } & Boxer, without $\mathrm{Hg}$ & \multicolumn{2}{|c|}{ Berdan $4.5 \mathrm{~mm}$} & $\mathrm{xxxx}$ \\
\hline \multicolumn{2}{|c|}{ Speed $\mathrm{v}_{0}$} & $360 \mathrm{~ms}^{-1}$ & $305 \mathrm{~ms}^{-1}$ & $377 \mathrm{~ms}^{-1}$ & $349 \mathrm{~ms}^{-1}$ \\
\hline \multicolumn{2}{|c|}{ Energy E $_{0}$} & $518 \mathrm{~J}$ & $451 \mathrm{~J}$ & $533 \mathrm{~J}$ & $454 \mathrm{~J}$ \\
\hline
\end{tabular}


Cast polycarbonate of $4 \mathrm{~mm}$ thickness was used for reinforcement of the test sample. Reinforcement of the test sample was done by connecting six polycarbonate boards of dimensions $510 \mathrm{~mm}$ x $510 \mathrm{~mm}$ x $24 \mathrm{~mm}$. Impact kinetic energy of shot $\mathrm{E}_{\mathrm{d}}$ was calculated according to equation (1). For calculation of limit impact speed of shot $\mathrm{v}_{\text {lim }}$, calculation according to equation (2) was used. To determine the penetration force of shot, the formula in DeMarre's form was applied. Calculation of values of kinetic energy and limit impact speed of used shots for overcoming of sheet metal resistance is listed in Table 7 [17].

Calculation of values of impact kinetic energy and limit impact speed of used shots for penetration of reinforced test sample [6]

Table 7

\begin{tabular}{|l|c|c|}
\hline Brand & $\boldsymbol{E}_{\boldsymbol{d}}(\boldsymbol{J})$ & $\boldsymbol{V}_{\text {lim }}\left(\boldsymbol{m s}^{-1}\right)$ \\
\hline 9mm LUGER ZVS & 482.76 & 1666.05 \\
\hline 9mm LUGER Subsonic & 451.17 & 1513.03 \\
\hline 9mm LUGER & 532.98 & 1346.37 \\
\hline Blazer 9mm LUGER & 453.71 & 1726.45 \\
\hline
\end{tabular}

The theoretical results imply that the limit impact speed necessary for penetration of the reinforced test sample (of thickness $\mathrm{s}=0.249 \mathrm{dm}$ ) is several times higher than the muzzle velocity $\mathrm{V}_{0}$ of used ammunition.

\section{Results of experimental testing}

Results of burglar resistance (with and without reinforcement by rock wool) which were measured by perpendicular shooting of the test sample from $10 \mathrm{~m}$ by different types of ammunition within the pilot project are listed in Table 8 [6].

Using rock wool, no verifiable or relevant results were acquired which could be utilized to increase burglar resistance of the test sample. For this purpose, the reinforcement was resolved using a set of six $24 \mathrm{~mm}$ thick polycarbonate boards within the main experiment. During the main experiment a shortening of distance between the muzzle and test sample in direction of shot to $5 \mathrm{~m}$ occured. Measured results are listed in Table 9.
Results of burglar resistance after reinforcement of test sample by set of $24 \mathrm{~mm}$ thick polycarbonate boards [6]

Table 9

\begin{tabular}{|l|c|c|}
\hline \multirow{2}{*}{ Ammunition } & \multirow{3}{*}{$\begin{array}{c}\text { Am } \\
\text { 9mm LUGER ZVS }\end{array}$} & $\begin{array}{c}\text { Depth of penetration channel } \\
\text { in polycarbonate board } \\
(\mathbf{m m})\end{array}$ \\
\hline \multirow{2}{*}{$5.10^{3}$} & 13.4 \\
\cline { 1 - 1 } & & 7.5 \\
\cline { 1 - 1 } 9mm LUGER Subsonic & 13.6 \\
\hline 9lazer 9mm LUGER & & penetration \\
\cline { 1 - 1 } & & \\
\cline { 1 - 1 }
\end{tabular}

Table 9 implies that the polycarbonate boards reinforced the test sample and prevented its penetration by all bullets except Blazer $9 \mathrm{~mm}$ LUGER which was able to penetrate it. Mathematical model was ineffective in this case. The reason of penetration is presumably the composition of shot core. Figure 2 displays the shot in polycarbonate board. Bullet Sellier\&Bellot $9 \mathrm{~mm}$ Luger Subsonic penetrated only the first layer. The second layer was disrupted, but all other four layers remained almost intact.

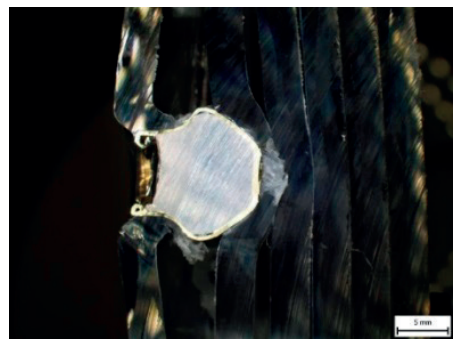

Fig. 2 Cross-section of bullet in polycarbonate board [6]

\section{Conclusion}

The experiment performed with a set of $24 \mathrm{~mm}$ thick polycarbonate boards proved significant increase of burglar resistance of the examined parts of chassis in a commercially produced personal motor vehicle (door). Only in one case, when using Blazer 9mm LUGER bullet, penetration occurred.

Results of burglar resistance (with and without reinforcement by rock wool) measured by perpendicular shooting of test sample within pilot project [6]

Table 8

\begin{tabular}{|c|c|c|c|c|}
\hline \multirow{4}{*}{ Ammunition } & \multirow{4}{*}{ Distance $(\mathrm{mm})$} & \multicolumn{3}{|c|}{ Depth of penetration in wall stopping the shots (depth + length of bullet) } \\
\hline & & \multicolumn{2}{|c|}{ Shot into test sample } & \multirow{2}{*}{ Difference } \\
\hline & & not reinforced & reinforced & \\
\hline & & \multicolumn{3}{|c|}{$(\mathrm{mm})$} \\
\hline RL 124 GRS FMJ & \multirow{4}{*}{$10^{4}$} & 107.743 & 162.369 & 54.626 \\
\hline Lapua Cepp & & 104.104 & 138.629 & 34.525 \\
\hline RL 124 GRS FMJ lead & & 89.755 & 18.717 & -71.038 \\
\hline Magtech & & 164.103 & 75.817 & -88.286 \\
\hline
\end{tabular}


These bullets are characteristic by their high penetration force. Further reinforcement is possible by adding another $4 \mathrm{~mm}$ thick polycarbonate board. For the purpose of passive protection of the motor vehicle crew it is not necessary to use material from armored boards, but also other materials, such as polycarbonate board can be used. Financial costs of both polycarbonate boards and of technical modifications of a vehicle are significantly lower than the previous costs of armor reinforcement. In the next period, possibilities of increasing burglar resistance of motor vehicles using ceramic materials and carbon fabrics shall be experimentally verified.

\section{References}

[1] PLANKA, B. et al.: Criminalistic Ballistics, Prague: Ales Cenek, 2009, 672 p., ISBN: 9788073800369.

[2] BS EN 1063:2000 - Glass in Building. Security Glazing. Testing and Classification of Resistance Against Bullet Attack. BSI. 2000.

[3] BS EN 1522:1999 - Windows, Doors, Shutters and Blinds. Bullet resistance. Requirements and Classification, BSI, 1999.

[4] STN EN 1523 - Windows, Doors, Shutters and Blinds. Bullet Resistance. Test Method (in Slovak), 2000.

[5] German DIN ballistic standard. German: DIN 52290 - Part 2, Nov. 1988.

[6] Own experiment: Exploration Burglar Resistance of Extracted Elements of Motor Vehicles, 2012 - 2014.

[7] VEGA project No. 1/098/11 Model of Integrated Security System Optimization Framework for Protection of Specific Objects Realised by Means of Expert System.

[8] MARTINCOVA, P., GRONDZAK, K., VAClAVKOVA, M.: Information System for Security Evaluation - Design and Implementation (in Slovak), Proc. of intern. conference on technics, technologies and education ICTTE 2013: October, 2013, Yambol, ISSN 1314-9474. - [S.1: s.n], 2013, pp. 251-256.

[9] KITTEL, L., LOVECEK, T.: Passive Protection Elements Breach Resistance Modeling, Communications - Scientific Letters of the University of Zilina, vol. 13, No. 2, 2011, pp. 53-58, ISSN 1335-4205.

[10] Ministry of Interior of the Slovak Republic, Number of registred weapons in the Slovak Republic, [on-line] http://www.minv. sk/?statisticke-prehlady-evidencie-zbrani.

[11] STN EN 771-4 - Specification for Masonry Units. Part 4: Autoclaved Aerated Concrete Masonry Units (AAC), 2013.

[12] EN AW 6106/ISO: Al MgSiMn. Aluminium and Aluminium Alloys - Chemical Composition and Form of wrought Products - Part 3: Chemical Composition; German version EN 573-3:1994.

[13] JURICEK, L., NOVOTNY, P.: Modeling of Small Arm Projectile Penetration Through a Steel Plate (in Czech). Vojenske zdravotnicke listy, vol. LXXIII, No. 1, 2004, ISSN 0372-7025.

[14] HALLQUIST, J., LS-DYNA: Keyword User's Manual. Nonlinear Dynamic Analyses of Structures. Livermore Software Technology Corporation, digital manual, May, 1999.

[15] IMAOKA, S.: Implicit vs. Explicit Dynamics. ANSYS, Inc. on 6.28.2001. www.ansys.net/ tnt_sheldon13.htm.

[16] SELLIER, K., KNEUBUHL, B.: Wundballistik und ihre ballistischen Grundlagen. 2. vollig uberarbeitete und erganzte Auflage. Berlin: Springer-Verlag, 2001, 526 p., ISBN 3-540-66604-4.

[17] MRAZ, J.: Practical Research for Design of Passenger Car's Body Increased Resilience (in Slovak). Diplomova praca, 2014, p. 91, odborny konzultant: Kamil Boc. 